\section{International Scientific Journal Theoretical \& Applied Science}

\author{
p-ISSN: 2308-4944 (print) e-ISSN: 2409-0085 (online) \\ Year: $2015 \quad$ Issue: 08 Volume: 28 \\ Published: $30.08 .2015 \quad \underline{\text { http://T-Science.org }}$
}

SECTION 3. Nanotechnology. Physics.
T. Yuvaraja

Assistant Professor,

Department of Electrical and Electronics Engineering, Sri Sairam College of Engineering,

Bangalore India

yuvarajastr@gmail.com

K. Ramya

Assistant Professor,

Department of Electrical and Electronics Engineering, Sri Sairam College of Engineering,

Bangalore India ramyaj.k14@gmail.com

\title{
ANALYSIS OF SPECTRUM HOLE IN DVB-T BAND
}

\begin{abstract}
Digital terrestrial television (DTV) covers an area with radius as large as $60 \mathrm{~km}$. FCC and Ofcom suggests detection of DTV signal at signal strength of as low as $-114 \mathrm{dBm}$ and $-120 \mathrm{dBm}$ respectively. Thus, Detection of DTV signals in low signal-to-noise ratio $(S N R)$ is vital. Continual pilot $(C P)$ positions in all the DTV signals are fixed. Digital Video Broadcasting Terrestrial (DVB-T), a DTV standard, is followed by most of the countries of the world. In this paper we propose a correlation based CP detection which can detect DVB-T signal at low SNR. One CP carrier was generated at the receiver which was correlated with the received orthogonal frequency division multiplexing (OFDM) signal sequence. The correlation coefficient was then compared with a threshold correlation coefficient to identify the existence of the CP to detect the presence of DVB-T signal and thereby spectrum hole. It was found from the simulation study for additive white Gaussian noise (AWGN) channel that signal detection at low SNR is possible compared to time domain symbol cross-correlation (TDSC) method.

Key words: Cognitive radio, continual pilot, correlation coefficient, DVB-T, spectrum sensing.

Language: English

Citation: Yuvaraja T, Ramya K (2015) ANALYSIS OF SPECTRUM HOLE IN DVB-T BAND. ISJ Theoretical \& Applied Science 08 (28): 1-8.

Soi: http://s-o-i.org/1.1/TAS-08-28-1 Doi: crossef http://dx.doi.org/10.15863/TAS.2015.08.28.1
\end{abstract}

\section{Introduction.}

Spatiotemporal underutilization of frequency spectrum has been reported in a survey report by federal communications commission (FCC) in 2004 [1]. Increasing the utilization of this valuable frequency spectrum can solve the present spectrum scarcity problem for wireless communications. The revolutionary concept of cognitive radio (CR) proposed by George Mitola [2] searches for spectrum hole into the allocated spectrum for different types of wireless services provided to licensed primary users (PUs) and utilizes the spatiotemporally free spectrum for efficient utilization of the spectrum. When a PU is activated, the CR system should discover it promptly and release that spectrum band and/or switch its operation to another available free band. Thus, detection of the presence of a PU is one of the most important tasks in CR systems.

Challenges faced by CR systems for spectrum sensing are: very low signal-to-noise ratio (SNR), channel uncertainty, fluctuating noise level with time, synchronization and so on. The simplest method to sense spectrum hole is energy detection
(ED), which evaluates the energy of the received signal for detection [3, 4]. Though ED is widely used in CR for its simplicity, it isn't robust to the noise uncertainty and thus, this method is unreliable.

Eigenvalue-based detection [5] improves the detection performance in presence of noise uncertainty and outperforms the ED for highly correlated signals. The drawback for eigenvaluebased detection is that it cannot distinguish PU signals from interferences. Waveform-based detection studied in [6] exploits the waveform of transmitted signal to decide whether the intended PU is active. It was shown that the method achieves a perfect performance if the priori information about PU is enough. The Cyclostationary feature detection method [7], which utilizes the cyclostationarity of the received signal, can meet the sensing requirements in $\mathrm{CR}$ without taking sensing time into account.

Television transmission in America, Canada, European countries, and Australia has already switched to digital terrestrial television (DTV). Digital video broadcasting-terrestrial (DVB-T) which has got popularity in Europe and most of the countries in Asia uses OFDM for transmission of 
DVB-T signal. The radius of coverage of DVB-T is about $60 \mathrm{~km}$ [8], which causes low signal strength as well as low SNR at the boundary. As a result sensing of OFDM signals at low SNR is of great importance for CR operation in DTV bands. One distinct feature of OFDM signals is in-band pilots multiplexed with data-carrying subcarriers. Utilization of pilot carriers for OFDM signal detection has got attention from the researchers.

In-band sensing in OFDM system without quiet period for $\mathrm{CR}$ system exploiting complementary symbol couple (CSC) in pilot signal has been proposed in [9]. In this paper the effect of channel and self- signal of the network was eliminated by utilizing the complementary condition of OFDM symbols. Then the power detection was performed over several OFDM frames. In this method the probability of detection varies with the number of observed frames for detection. However, its detection performance is limited since only a part of pilot symbols satisfies the complementary condition An unsynchronized, random timing 0 ffset and carrier frequency offset robust sensing technique with the hybrid domain signal processing which matched the received OFDM signals with a local pilot reference was proposed in [10].

Timing average of the received OFDM signal segments was also done to improve the performance at low SNR. The detection probability of 0.9 was achieved in [11] by performing detection process over approximately 85 OFDM symbols. The methods proposed in $[9,10,11]$ slow down the detection process as they require multiple OFDM symbols for sensing. In [12] a novel non-quiet PU detection scheme, which is based on pilot cancellation [13] of the CR transmitted known pilot signal is proposed. The performance of the proposed scheme was demonstrated only when the ED is applied. Compared to the detection scheme in [9], the scheme proposed in [12] can achieve better detection performance exploiting all OFDM symbols of pilot subcarriers for PU detection.

A novel spectrum sensing scheme for DVB-T system that is proposed in [14], partitions the correlation values between the continual pilots $(\mathrm{CP})$ and scattered pilots (SP) nearest to the CPs into several groups based on the sample distance between the $\mathrm{CP}$ and SP, and then, eliminates the effect of timing synchronization error by recorrelating the correlation values in the same group. An algorithm which needs multiple OFDM symbols to detect spectrum hole into DVB-T spectrum by time domain autocorrelation of pilot signals presented in [15], is also able to differentiate single tone spurious with DVB-T signal. Time domain symbol correlation (TDSC) method of spectrum whole identification is proposed in [16]. TDSC method chooses OFDM symbols in couples and their correlations are found. These correlations are averaged to find decision static. This method suffers from speed of detection as it employs multiple OFDM symbols for detection.

CPs and SPs are transmitted in DVB-T OFDM symbols with 4/3 times boosted amplitude compared to the data carriers. In addition CP positions are fixed in all DVB-T OFDM symbols [17]. When noise power is as strong as data carriers, the $\mathrm{CP}$ carriers having higher power is expected to give higher SNR compared to data carriers and transmission parameter signal (TPS) carriers. In this paper we have used the correlation method to identify the existence of an expected CP into DVB-T signal and thereby make the detection decision. At the receiver a locally generated OFDM CP carrier of the target DVB-T band was generated and correlated to the received discrete time noisy signal. The correlation coefficient was then compared to threshold correlation coefficient to identify the existence of the $\mathrm{CP}$ and thereby DVB-T PU signal. Detection performance of this method at different SNR level shows its capability to detect signal at low power and low SNR condition.

\section{DVB-T OFDM System}




\begin{tabular}{|c|c|c|c|c|c|c|}
\hline Impact Factor: & $\begin{array}{l}\text { ISRA (India) } \\
\text { ISI (Dubai, UAF } \\
\text { GIF (Australia) } \\
\text { JIF }\end{array}$ & $\begin{array}{l}=1.344 \\
=0.829 \\
=0.356 \\
=1.500\end{array}$ & $\begin{array}{l}\text { SIS (USA) } \\
\text { PИНЦ (Russia) } \\
\text { ESJI (KZ) } \\
\text { SJIF (Morocco) }\end{array}$ & $\begin{array}{l}=0.912 \\
=0.179 \\
=1.042 \\
=\mathbf{2 . 0 3 1}\end{array}$ & ICV (Poland) & $=6.630$ \\
\hline
\end{tabular}

Table 1

DVB-T OFDM $2 K$ and $8 K$ parameters.

\begin{tabular}{|c|c|c|c|c|c|c|c|}
\hline \multicolumn{2}{|l|}{ Mode of operation } & \multicolumn{3}{|l|}{$2 \mathrm{~K}$} & \multicolumn{3}{|l|}{$8 \mathrm{~K}$} \\
\hline \multicolumn{2}{|c|}{ Number of useful sub-Carriers, $M$} & \multicolumn{3}{|l|}{1705} & \multicolumn{3}{|l|}{6817} \\
\hline \multicolumn{2}{|c|}{ Value of Carrier Number, $K_{\max }$} & \multicolumn{3}{|l|}{1704} & \multicolumn{3}{|l|}{6816} \\
\hline \multicolumn{2}{|c|}{ Value of Carrier Number, $K_{\min }$} & \multicolumn{3}{|l|}{0} & \multicolumn{3}{|l|}{0} \\
\hline \multicolumn{2}{|c|}{ Number of Continual Pilots $\left(M_{\mathrm{CP}}\right)$} & \multicolumn{3}{|l|}{45} & \multicolumn{3}{|l|}{177} \\
\hline \multicolumn{2}{|c|}{ Number of Scattered Pilots $\left(M_{\mathrm{SP}}\right)$} & \multicolumn{3}{|l|}{141} & \multicolumn{3}{|l|}{564} \\
\hline \multicolumn{2}{|c|}{$\begin{array}{l}\text { Spacing between carriers } K_{\min } \text { and } \\
K_{\max }, \frac{K-1}{T \mathrm{u}}(M H z)\end{array}$} & 5.71 & 6.66 & 7.61 & 5.71 & 6.66 & 7.61 \\
\hline \multicolumn{2}{|c|}{$\begin{array}{l}\text { Bandwidth of RF channel, } \\
B W(\mathrm{MHz})\end{array}$} & 6 & 7 & 8 & 6 & 7 & 8 \\
\hline \multicolumn{2}{|c|}{ Elementary Period, $T=\frac{7}{8 B W}(\mu s)$} & $7 / 48$ & $7 / 56$ & $7 / 64$ & $7 / 48$ & $7 / 56$ & $7 / 64$ \\
\hline \multicolumn{2}{|c|}{ Symbol Duration, $\mathrm{Tu}(\mu s)$} & 299 & 256 & 224 & 1195 & 1024 & 896 \\
\hline \multicolumn{2}{|c|}{ Sub-Carrier Spacing, $\frac{1}{T \mathrm{u}}(\mathrm{Hz})$} & 3348 & 3906 & 4464 & 837 & 977 & 1116 \\
\hline \multirow[t]{4}{*}{ Guard Interval, $T_{\mathrm{g}}$} & $1 / 4$ & $75 \mu \mathrm{s}$ & $64 \mu \mathrm{s}$ & $56 \mu \mathrm{s}$ & $299 \mu \mathrm{s}$ & $256 \mu \mathrm{s}$ & $224 \mu \mathrm{s}$ \\
\hline & $1 / 8$ & $37 \mu \mathrm{s}$ & $32 \mu \mathrm{s}$ & $28 \mu \mathrm{s}$ & $149 \mu \mathrm{s}$ & $128 \mu \mathrm{s}$ & $112 \mu \mathrm{s}$ \\
\hline & $1 / 16$ & $19 \mu \mathrm{s}$ & $16 \mu \mathrm{s}$ & $14 \mu \mathrm{s}$ & $75 \mu \mathrm{s}$ & $64 \mu \mathrm{s}$ & $56 \mu \mathrm{s}$ \\
\hline & $1 / 32$ & $9 \mu \mathrm{s}$ & $8 \mu \mathrm{s}$ & $7 \mu \mathrm{s}$ & $37 \mu \mathrm{s}$ & $32 \mu \mathrm{s}$ & $28 \mu \mathrm{s}$ \\
\hline
\end{tabular}

2.1. The DVB-T OFDM signal is organized in frames, each frame has duration of TF and consists of 68 OFDM symbols induced from 0 to 67. Four frames constitute one super frame. Each symbol is set by $K=6817$ carriers in $8 \mathrm{Kmode}$ and $\mathrm{K}=1705$ carrier in the $2 \mathrm{~K}$ mode and transmitted with duration TG.

Scattered pilot (SP): inserted in every 12th subcarrier. The location of these pilot subcarriers are offset three subcarriers in consecutive DVB-T OFDM symbols. SPs repeat their pattern every 4 consecutive symbols.

CP carriers: inserted in every OFDM symbol. $2 K$ mode contains $45 \mathrm{CPs}$ and $8 K$ mode contains 177 CPs.

TPS carriers: locations are constant and defined by the standard and all carriers convey the same information.

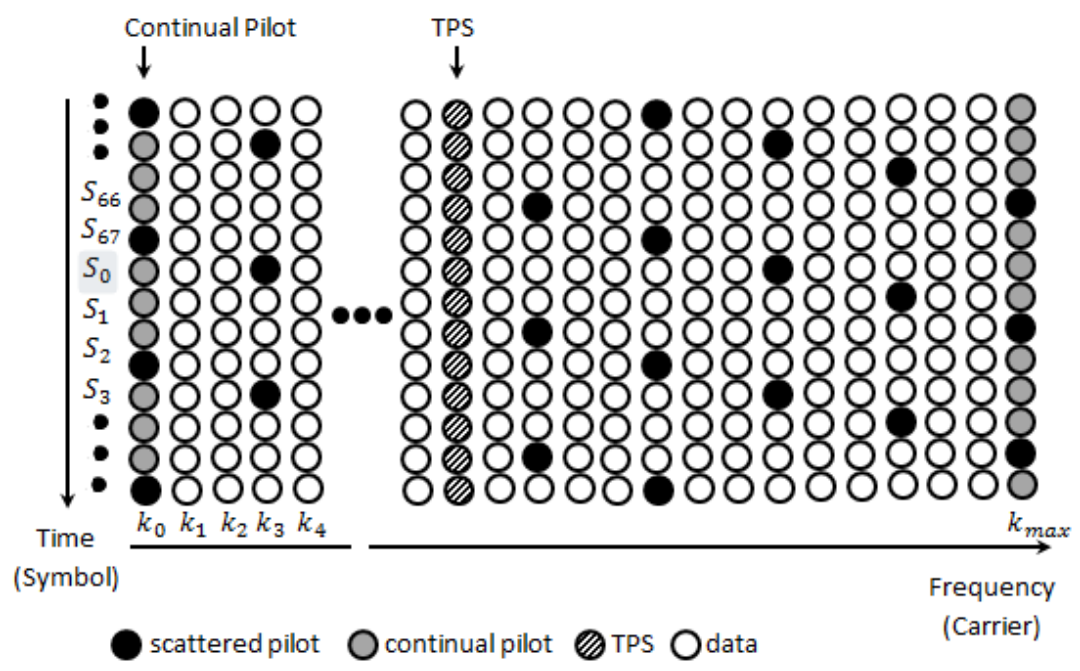

Figure 1 - Transmission Frame for the DVB-T 2K Mode. 
It has been shown in [18] that the $2 \mathrm{~K}$ mode is more suitable for mobile DVB-T reception due to the four times larger carrier-spacing it produces which has also been proved in practical test. In this paper, we implemented/realized one symbol of the DVB-T $2 \mathrm{~K}$ system of European standard $8 \mathrm{MHz}$ bandwidth by an inverse fast Fourier transform (IFFT) at the transmitter and a fast Fourier transform (FFT) at the receiver by taking DVB-T parameters into account as shown in table 1.

\section{DVB-T Signal Detection Hypothesis}

The primary goal of DVB-T spectrum sensing is to determine whether the DTV channel is occupied by a PU or is vacant. The problem of determining a DVB-T signal on a specific spectrum band can be categorized into the binary hypothesis, where, the null hypothesis $H 1$ corresponding to DVB-T signal absent and the alternative hypothesis $H 1$ corresponding to DVB-T signal existing. These two hypotheses can be represented with the expressions as given in Equation (1) below:

$$
H_{o}: y(n)=w(n)
$$

and

$$
H_{1}: y(n)=x(n)+w(n)
$$

where $x(n)$ is the DVB-T OFDM-based primary user signal including data signals $x d(n)$ and pilot signals $x p(n)$ which consist of the CPs and SPs. $y(n)$ represents the $n$th sample of received signal and $w(n)$ is the additive white Gaussian noise (AWGN) with a complex normal distribution $\mathcal{N} c(0, \sigma w 2)$.

\subsection{TDSC Method of DVB-T spectrum detection} [15]

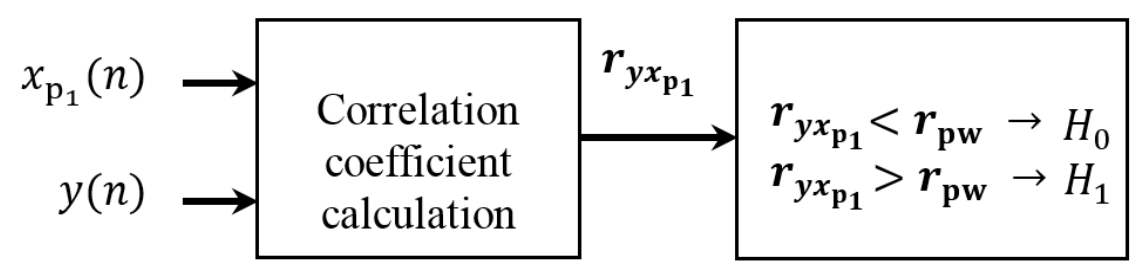

Figure 2 - Block diagram of the DVB-T PU detector.

$$
y(n)=x(n)+w(n)
$$

Where $\mathrm{w}(\mathrm{n})$ is the AWGN and

$$
x(n)=x_{p}(n)+x_{d}(n)
$$

The decision statistic of the TDSC NeymanPearson (NP) test is given by Equation (2) as follows:

$$
T_{N P}=\left|\frac{1}{S_{v}} \sum_{m-l=v} R(i, m)\right|
$$

Where $s v$ is the number of terms in correlation $R(l, m)$ that are accumulated and added, $\mathrm{S} v$ is the symbol index difference of the two OFDM symbols.

\section{Proposed Spectrum Detection System Model}

We consider one symbol of a DVB-T OFDM $2 \mathrm{~K}$ system with $\mathrm{M}=1705 \mathrm{sub}$-carriers, the high-speed binary serial input stream is denoted as $\{b i\}$. After serial to parallel $(\mathrm{S} / \mathrm{P})$ conversion a new parallel signal sequence, $X=\{d 0, d 1, d 2, \ldots, d k, \ldots, d M-1\}$ is obtained. $\{d k\}$ is considered to hold values from $\{0,1\}$ and when $k$ is CP index as shown in Table 2, $\{d k\}$ holds the value from $\{1\}$. Each element of parallel signal sequence is supplied to $M$ orthogonal sub-carriers $\{e-i 2 \pi f 0 t, e-i 2 \pi f 1 t, \ldots, e-i 2 \pi f M-1 t\}$ for modulation, respectively. During modulation the CP and SP carriers are boosted 4/3 times compared to data carriers. Finally, modulated signals are added together to form an OFDM symbol. By IDFT complex envelope of the transmitted OFDM signals can be written as

$$
x(n)=\frac{1}{M} \sum_{k=0}^{K_{\max }} X_{k} e^{j 2 \pi f k^{n}},
$$

$f_{k}=k \Delta f, \Delta f$ is sub carrier spacing and $\mathrm{K}$ is sub carrier index.

The baseband representation of the signal received at the receiver is 


\begin{tabular}{|c|c|c|c|c|c|c|}
\hline Impact Factor: & $\begin{array}{l}\text { ISRA (India) } \\
\text { ISI (Dubai, UAE } \\
\text { GIF (Australia) } \\
\text { JIF }\end{array}$ & $\begin{array}{l}=1.344 \\
=0.829 \\
=0.356 \\
=1.500\end{array}$ & $\begin{array}{l}\text { SIS (USA) } \\
\text { PИНЦ (Russia) } \\
\text { ESJI (KZ) } \\
\text { SJIF (Morocco) }\end{array}$ & $\begin{array}{l}=0.912 \\
=0.179 \\
=1.042 \\
=2.031\end{array}$ & ICV (Poland) & $=6.630$ \\
\hline
\end{tabular}

$$
x(n)=\frac{1}{m}\left(\sum_{g \mathrm{EA}} X_{p g}(n)\left(\frac{4}{3}\right) e^{j 2 \Pi g^{n}}+\sum_{m \mathrm{~EB}} X_{p m}(n)\left(\frac{4}{3}\right) e^{j 2 \Pi f n^{n}}+\sum_{q \mathrm{EC}} X_{p q} l m e^{j 2 \Pi f q^{n}}+\sum_{\forall E e} x d v(n)\right)
$$

where $\mathrm{A}, \mathrm{B}, \mathrm{C}$, and $\mathrm{E}$ are sets of $\mathrm{CP}$ indices, $\mathrm{SP}$ indices, TPS indices, and data carriers respectively.

Thus by Equation (4) and (5),

$$
y(n)=\frac{1}{m}\left(\begin{array}{l}
\left.\sum_{g \varepsilon a} X_{p g}(n)\left(\frac{4}{3}\right) e^{j 2 \pi f g^{n}}+\sum_{m \varepsilon b} X_{p m}(n)\left(\frac{4}{3}\right) e^{j 2 \pi f m^{n}}+\sum_{q \varepsilon c} X_{p q}(n)\left(\frac{4}{3}\right) e^{j 2 \pi f q^{n}}+\right) \\
\sum_{v \varepsilon e} X_{p v}(n) e^{j 2 \pi f v^{n}}+\sum_{k}^{k=k}=0 \text { max }{ }_{k} e^{j 2 \pi f k^{n}}
\end{array}\right)
$$

The generated pilot at the receiver is

$$
X_{p 1}(n)=a e^{-j 2 \pi f p 1^{n}}
$$

Here a is amplitude

Caculation of $y(n)$ and $x p_{1}(n)$ from (6) and (7).

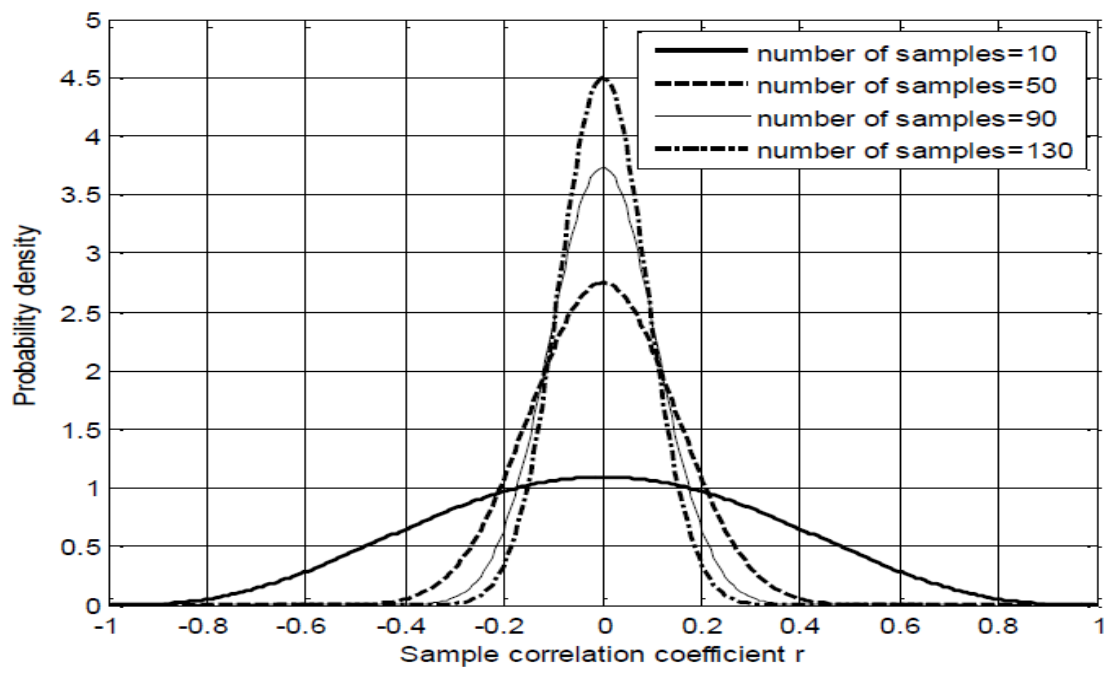

Figure 3 - Sampling distribution of correlation coefficient $\boldsymbol{r}$.

It is seen from the distribution shown in Figure 3 that as the number of samples increase, the correlation distribution curve becomes steep representing the improvement of accuracy over the expected value of correlation. For the experiment we correlate the generated sinusoidal carrier with AWGN noise 10,000 times and choose the 9000th maximum correlation value from the minimum to be the threshold to maintain the detection probability to

$$
\mathrm{R}_{\mathrm{yxp} 1}(1)=\frac{1}{\mathrm{~m}} \sum_{\mathrm{n}=0}^{\mathrm{n}=\mathrm{m}-1} \mathrm{y}(\mathrm{n}) \mathrm{ae}^{-\mathrm{j} 2 \pi \mathrm{fp} 1^{(\mathrm{n}-\mathrm{l})}}
$$

$$
\gamma_{\mathrm{pw}}=\mathrm{E}\left[\frac{\left(\mathrm{X}_{\mathrm{p} 1}(\mathrm{n})-\mu \mathrm{X}_{\mathrm{a}}\right)\left(\omega(\mathrm{n})-\mu_{\omega}\right)}{\sigma_{\mathrm{xp} 1} \sigma_{\omega}}\right]
$$

$\mu x p 1 \& \mu \omega$ are mean of pilot carrier.

0.9 and false alarm rate to 0.1 which was found to be $r \mathrm{pw}=0.0035$. The threshold $r \mathrm{pw}$ shall be changed depending on the required false alarm rate. 


\begin{tabular}{|c|c|c|c|c|c|}
\hline Impact Factor: & $\begin{array}{l}\text { ISRA (India) } \\
\text { ISI (Dubai, UAB } \\
\text { GIF (Australia) } \\
\text { JIF }\end{array}$ & $\begin{array}{l}=1.344 \\
=0.829 \\
=0.356 \\
=1.500\end{array}$ & $\begin{array}{l}\text { SIS (USA) } \\
\text { PИНЦ (Russia } \\
\text { ESJI (KZ) } \\
\text { SJIF (Morocco }\end{array}$ & $\begin{aligned}= & 0.912 \\
= & 0.179 \\
= & \mathbf{1 . 0 4 2} \\
= & \mathbf{2 . 0 3 1}\end{aligned}$ & ICV (Poland) \\
\hline
\end{tabular}

\section{Results and Discussions}

The simulation study was done at different levels of SNR. Different SNR values were achieved by changing the signal strength so that the signal strengths prescribed by FCC and Ofcom and its corresponding SNR can be maintained in the experiment. AWGN was fixed to zero mean and one standard deviation throughout the experiment. Table 2 shows the signal power in $\mathrm{dBm}$, corresponding $\mathrm{SNR}$ in $\mathrm{dB}$, and false alarm rate at different values of correlation threshold $r$ pw. It can be seen from Table 2 that the probability of false alarm increases as the detection threshold $r \mathrm{pw}$ is decreased but remains approximately invariant at different SNR values.

Table 2

False alarm rate for different SNR and signal power at different levels of threshold, $r$ pw and AWGN of $\operatorname{CN}(\mathbf{0 , 1})$.

\begin{tabular}{|c|c|c|c|c|}
\hline \multirow{2}{*}{ Signal Power $(\mathrm{dBm})$} & \multirow{2}{*}{ SNR $(\mathrm{dB})$} & \multicolumn{3}{|c|}{ Probability of false alarm for correlation Threshold, $r_{p w}$} \\
\cline { 3 - 5 } & & 0.0035 & 0.003 & 0.0026 \\
\hline-66.65 & -96.65 & 0.02 & 0.11 & 0.20 \\
\hline-60.63 & -90.63 & 0.03 & 0.08 & 0.22 \\
\hline-57.10 & -87.10 & 0.03 & 0.08 & 0.21 \\
\hline-51.09 & -81.09 & 0.03 & 0.09 & 0.30 \\
\hline-49.74 & -79.74 & 0.03 & 0.06 & 0.23 \\
\hline-46.65 & -76.65 & 0.03 & 0.12 & 0.21 \\
\hline
\end{tabular}

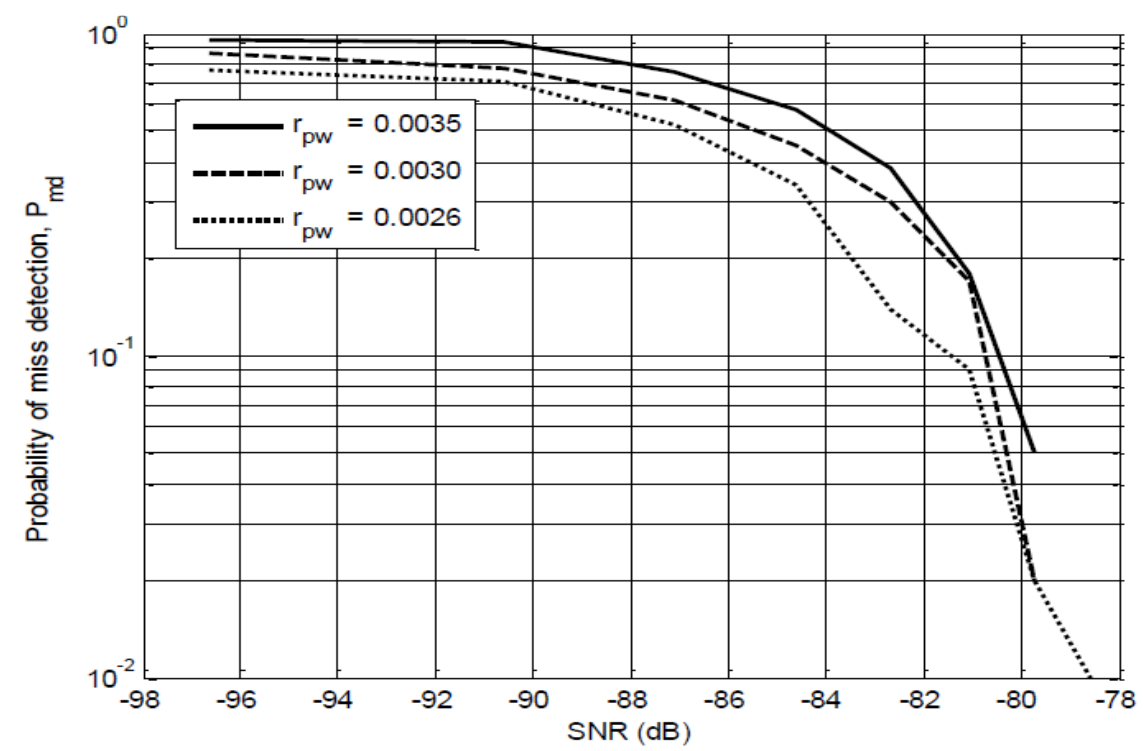

Figure 4 - The probability of miss detection for different values of correlation threshold $r p w$.

where $\mathrm{A}, \mathrm{B}, \mathrm{C}$, and $\mathrm{E}$ are sets of $\mathrm{CP}$ indices, $\mathrm{SP}$ indices, TPS indices, and data carriers respectively.

Thus by Equation (4) and (5), 


\begin{tabular}{|c|c|c|c|c|c|c|}
\hline Impact Factor: & $\begin{array}{l}\text { ISRA (India) } \\
\text { ISI (Dubai, UAE } \\
\text { GIF (Australia) } \\
\text { JIF }\end{array}$ & $\begin{array}{l}=1.344 \\
=0.829 \\
=0.356 \\
=1.500\end{array}$ & $\begin{array}{l}\text { SIS (USA) } \\
\text { PИНЦ (Russia) } \\
\text { ESJI (KZ) } \\
\text { SJIF (Morocco) }\end{array}$ & $\begin{array}{l}=0.912 \\
=0.179 \\
=1.042 \\
=\mathbf{2 . 0 3 1}\end{array}$ & ICV (Poland) & $=6.630$ \\
\hline
\end{tabular}

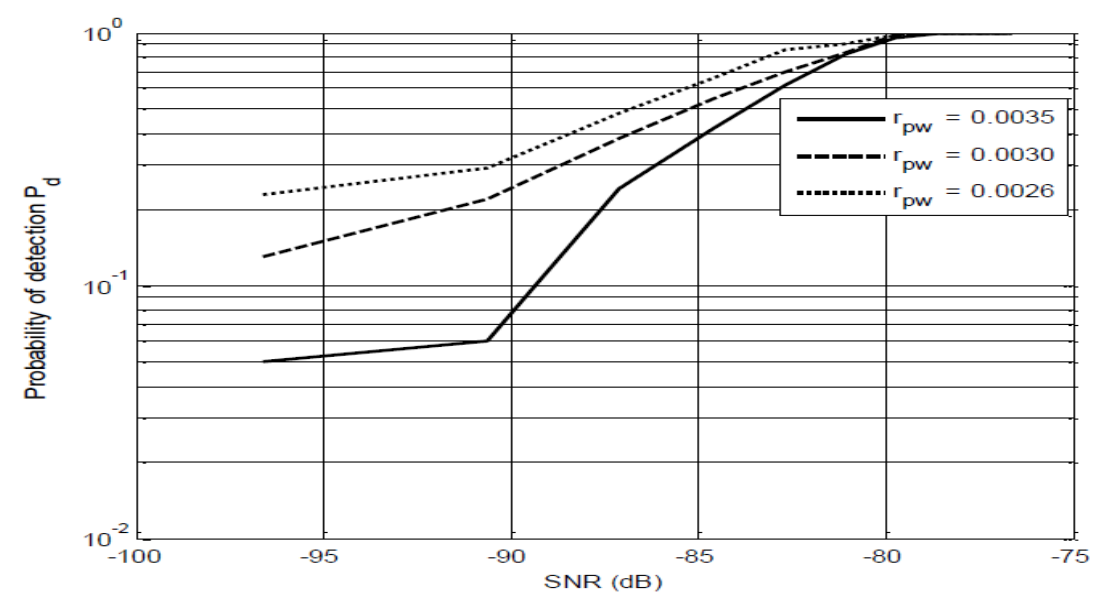

Figure 5 - The probability of detection for different values of correlation threshold, $r$ pw .

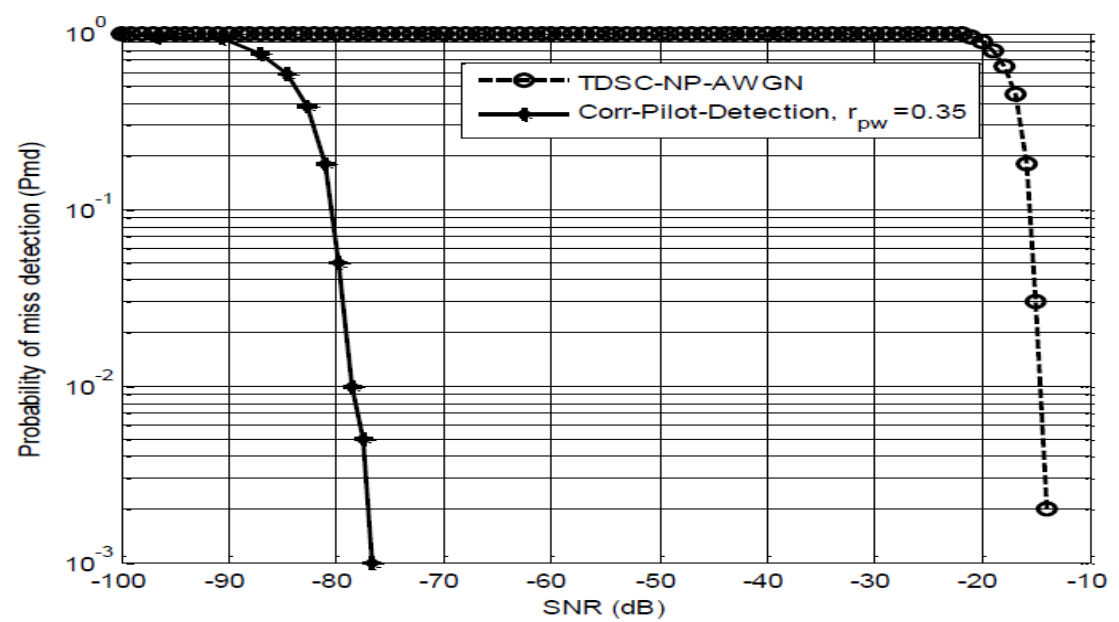

Figure 6 - Comparison of Correlation based method to TDSC-NP-AWGN method of detection.

Figure 4 and 5 depicts the SNR versus the probability of miss detection and the probability of detection curves at three values of rpw. As can be seen the probability of miss detection increase and the probability of detection decrease with the increase of threshold correlation coefficient rpw. From Figure 4 we can see that at SNR of $-90 \mathrm{~dB}$ the probability of miss detection is 0.9 for $\mathrm{rpw}=0.0035$. In addition the probability of miss detection decreases as threshold decreases. From Figure 5 it is marked that the probability of detection, $\mathrm{Pd}=0.9$ and 0.99 at SNR of approximately $-81 \mathrm{~dB}$ and $-79 \mathrm{~dB}$ correspondingly. From Table 3 signal strength that corresponds to $-81 \mathrm{~dB}$ and $-79 \mathrm{~dB}$ of SNR are $51.09 \mathrm{dBm}$ and $-49.74 \mathrm{dBm}$ approximately. The false alarm rate at the corresponding SNR values is 0.03 which is much below the required false alarm rate of 0.1 .

Figure 6 shows a comparative study of the proposed correlation coefficient based CP detection method to NP based TDSC detection method for AWGN channel (TDSC-NP-AWGN [15]) in terms of the probability of miss detection. For TDSC method $P$ md $=0.9$ at SNR $-22 d B$. The probability of miss detection of 0.1 can be seen at SNR $-81 d B$ and $-15 d B$ for proposed correlation based $\mathrm{CP}$ detection method and TDSC-NP-AWGN methods accordingly. This result shows the possibility of using our proposed correlation based CP detection method in $\mathrm{CR}$ communications where detection is required at low signal strength and low SNR.

\section{Conclusions}

A correlation based DVB-T signal detection method is proposed in this paper where received signal was correlated to a generated known CP. It was found that this method can detect signal efficiently in low SNR and at very low signal level. The proposed method requires only one symbol to be received and correlated to the generated carrier. Thus authors expect that this method will speed up the detection process if implemented as it senses the 


\begin{tabular}{|c|c|c|c|c|c|c|}
\hline Impact Factor: & $\begin{array}{l}\text { ISRA (India) } \\
\text { ISI (Dubai, UAF } \\
\text { GIF (Australia) } \\
\text { JIF }\end{array}$ & $\begin{array}{r}=1.344 \\
=0.829 \\
=0.356 \\
=1.500\end{array}$ & $\begin{array}{l}\text { SIS (USA) } \\
\text { PИHЦ (Russia) } \\
\text { ESJI (KZ) } \\
\text { SJIF (Morocco) }\end{array}$ & $\begin{array}{l}=0.912 \\
=0.179 \\
=1.042 \\
=2.031\end{array}$ & ICV (Poland) & $=6.630$ \\
\hline
\end{tabular}

channel for one OFDM symbol duration and need to process less number of samples where sensing is performed over multiple symbols or multiple frames. As future work the authors wish to simulate the performance of the proposed method on different channel conditions.

\section{References:}

1. (2004) Federal Communications Commission. 2004, Notice of proposed rulemaking FCC04113: Unlicensed operation in the TV broadcast bands. Washington, D.C., USA.

2. Mitola J, Maguire GQ (1999) Cognitive radio: Making software radios more personal. IEEE Pers. Commun. 1999, DOI: 10.1109/98.788210.

3. Urkowitz H (1967) Energy detection of unknown deterministic signals. P. IEEE. 1967, DOI: 10.1109/PROC.1967.5573.

4. Digham FF, Alouini MS, Simon MK (2007) On the Energy Detection of Unknown Signals Over Fading Channels. IEEE T. Commun. 2007, DOI: 10.1109/TCOMM.2006.887483.

5. Cabric D, Tkachenko A, Brodersen RW (2006) Spectrum Sensing Measurements of Pilot,
Energy, and Collaborative Detection. IEEE Military Communications Conference. 2006, DOI: 10.1109/MILCOM.2006.301994.

6. Kim M, Po K, Takada JI (2010) Performance Enhancement of Cyclostationarity Detector by Utilizing Multiple Cyclic Frequencies of OFDM signals. IEEE Symposium on New Frontiers in Dynamic Spectrum. 2010, DOI: 10.1109/DYSPAN.2010.5457876.

7. Yonghong Z, Ying-chang L (2009) EigenvalueBased Spectrum Sensing Algorithms for Cognitive Radio. IEEE T. Commun. 2009, DOI: 10.1109/TCOMM.2009.06.070402.

8. Chen D, Li J, Ma J (2008) In-Band Sensing without Quiet Period in Cognitive Radio. IEEE WCNC. 2008, DOI: 10.1109/WCNC.2008.133. 